\title{
Front Matter: Volume 10443
}

, "Front Matter: Volume 10443," Proc. SPIE 10443, Second International Workshop on Pattern Recognition, 1044301 (19 June 2017); doi: $10.1117 / 12.2282432$

Event: Second International Workshop on Pattern Recognition, 2017, Singapore, Singapore 


\title{
PROCEEDINGS OF SPIE
}

\section{Second International Workshop on Pattern Recognition}

\author{
Xudong Jiang \\ Masayuki Arai \\ Guojian Chen \\ Editors
}

1-3 May 2017

Singapore

Organized by

ACM Singapore Chapter (Singapore)

Hainan University (China)

Sponsored by

Chengdu Zonghang Exhibition \& Service Company, Ltd. (China)

Published by

SPIE 
The papers in this volume were part of the technical conference cited on the cover and title page. Papers were selected and subject to review by the editors and conference program committee. Some conference presentations may not be available for publication. Additional papers and presentation recordings may be available online in the SPIE Digital Library at SPIEDigitallibrary.org.

The papers reflect the work and thoughts of the authors and are published herein as submitted. The publisher is not responsible for the validity of the information or for any outcomes resulting from reliance thereon.

Please use the following format to cite material from these proceedings:

Author(s), "Title of Paper," in Second International Workshop on Pattern Recognition, edited by Xudong Jiang, Masayuki Arai, Guojian Chen, Proceedings of SPIE Vol. 10443 (SPIE, Bellingham, WA, 2017) Seven-digit Article CID Number.

ISSN: 0277-786X

ISSN: 1996-756X (electronic

ISBN: 9781510613508

ISBN: 9781510613515 (electronic)

Published by

SPIE

P.O. Box 10, Bellingham, Washington 98227-0010 USA

Telephone +1 3606763290 (Pacific Time) · Fax +1 3606471445

SPIE.org

Copyright (c) 2017, Society of Photo-Optical Instrumentation Engineers.

Copying of material in this book for internal or personal use, or for the internal or personal use of specific clients, beyond the fair use provisions granted by the U.S. Copyright Law is authorized by SPIE subject to payment of copying fees. The Transactional Reporting Service base fee for this volume is $\$ 18.00$ per article (or portion thereof), which should be paid directly to the Copyright Clearance Center (CCC), 222 Rosewood Drive, Danvers, MA 01923. Payment may also be made electronically through CCC Online at copyright.com. Other copying for republication, resale, advertising or promotion, or any form of systematic or multiple reproduction of any material in this book is prohibited except with permission in writing from the publisher. The CCC fee code is 0277-786X/17/\$18.00.

Printed in the United States of America.

Publication of record for individual papers is online in the SPIE Digital Library.

\section{SPIE. DIGRARY}

Paper Numbering: Proceedings of SPIE follow an e-First publication model. A unique citation identifier (CID) number is assigned to each article at the time of publication. Utilization of CIDs allows articles to be fully citable as soon as they are published online, and connects the same identifier to all online and print versions of the publication. SPIE uses a seven-digit CID article numbering system structured as follows:

- The first five digits correspond to the SPIE volume number.

- The last two digits indicate publication order within the volume using a Base 36 numbering

system employing both numerals and letters. These two-number sets start with 00, 01, 02, 03, 04, 05, 06, 07, 08, 09, OA, OB ... 0Z, followed by 10-1Z, 20-2Z, etc. The CID Number appears on each page of the manuscript. 


\title{
Contents
}

\author{
vii Authors \\ ix Conference Committees \\ xiii Introduction
}

\section{SESSION 1}

TARGET RECOGNITION AND TRACKING

1044302 Artificial intelligence tools for pattern recognition [10443-40]

1044303 Eye movement identification based on accumulated time feature [10443-21]

1044304 Facades structure detection by geometric moment [10443-67]

1044305 A natural approach to convey numerical digits using hand activity recognition based on hand shape features [10443-6]

1044306 Multiclass multiple kernel learning for HRRP-based radar target recognition [10443-11]

1044307 Degraded Chinese rubbing images thresholding based on local first-order statistics [10443-35]

1044308 Towards discrete wavelet transform-based human activity recognition [10443-45]

1044309 Pattern recognition of concrete surface cracks and defects using integrated image processing algorithms [10443-73]

10443 OA Recognizing Chinese characters in digital ink from non-native language writers using hierarchical models [10443-4]

10443 OB Fault prevention by early stage symptoms detection for automatic vehicle transmission using pattern recognition and curve fitting [10443-69]

10443 OC Improved convolutional networks in forest species identification task [10443-58]

10443 OD Research and implementation of finger-vein recognition algorithm [10443-8]

10443 OE Comparison expert and novice scan behavior for using e-learning [10443-64]

10443 OF Driver face tracking using semantics-based feature of eyes on single FPGA [10443-30] 
10443 OG Finessing filter scarcity problem in face recognition via multi-fold filter convolution [10443-47]

$10443 \mathrm{OH} \quad$ Method for secure electronic voting system: face recognition based approach [10443-55]

10443 Ol Video-based face recognition via convolutional neural networks [10443-26]

10443 0J Application of OpenCV in Asus Tinker Board for face recognition [10443-27]

10443 OK Multimodal recognition based on face and ear using local feature [10443-43]

$10443 \mathrm{OL} \quad$ Upright detection of in-plain rotated face images with complicated background for organizing photos [10443-10]

10443 OM Face pose tracking using the four-point algorithm [10443-38]

\section{SESSION $3 \quad$ IMAGE SEGMENTATION}

10443 ON Multiple images segmentation based on saliency map [10443-18]

1044300 Carotid artery B-mode ultrasound image segmentation based on morphology, geometry and gradient direction [10443-59]

10443 OP Automatic airline baggage counting using 3D image segmentation [10443-9]

$104430 Q \quad$ Automated segmentation and isolation of touching cell nuclei in cytopathology smear images of pleural effusion using distance transform watershed method [10443-66]

\section{SESSION 4 IMAGE TRANSFORMATION AND ANALYSIS}

10443 OR Long-range correlation and wavelet transform analysis of solar magnetic activity [10443-57]

10443 OS Research on image registration based on D-Nets [10443-51]

10443 OT Blind technique using blocking artifacts and entropy of histograms for image tampering detection [10443-37]

10443 OU Smart mapping for quick detection of dissimilar binary images [10443-28]

10443 OV Content-based image retrieval using scale invariant feature transform and gray level co-occurrence matrix [10443-53]

$10443 \mathrm{OW} \quad$ Comparing the performance of different ultrasonic images enhancement for speckle noise reduction in ultrasound images using techniques: a preference study [10443-20]

10443 OX Action description using point clouds [10443-42] 
10443 OY A new non-uniformity correction method based on unidirectional variational model [10443-62]

$104430 Z$ SVM-based automatic diagnosis method for keratoconus [10443-44]

1044310 Automatic bone outer contour extraction from B-modes ultrasound images based on local phase symmetry and quadratic polynomial fitting [10443-60]

1044311 Facial fluid synthesis for assessment of acne vulgaris using luminescent visualization system through optical imaging and integration of fluorescent imaging system [10443-71]

1044312 Experiments on automatic classification of tissue malignancy in the field of digital pathology [10443-29]

\section{SESSION $6 \quad$ IMAGE PROCESSING AND APPLICATIONS}

1044313 Color vision deficiency compensation for Visual Processing Disorder using Hardy-Rand-Rittler test and color transformation [10443-70]

1044314 Profiling and sorting Mangifera Indica morphology for quality attributes and grade standards using integrated image processing algorithms [10443-65]

1044315 Progressive 3D shape abstraction via hierarchical CSG tree [10443-13]

1044316 Lane marking detection based on waveform analysis and CNN [10443-7]

1044317 Interactive QR code beautification with full background image embedding [10443-23]

1044318 Gaze inspired subtitle position evaluation for MOOCs videos [10443-22]

1044319 Single image super-resolution based on image patch classification [10443-50]

$104431 \mathrm{~A} \quad$ Training strategy for convolutional neural networks in pedestrian gender classification [10443-54]

10443 1B Development of intelligent surveillance system (ISS) in region of interest (ROI) using Kalman filter and camshift on Raspberry Pi 2 [10443-46]

10443 1C Video error concealment using block matching and frequency selective extrapolation algorithms [10443-49]

10443 ID Part-based deep representation for product tagging and search [10443-34]

10443 1E The filling-in function of the Bayesian AutoEncoder Network [10443-72] 
10443 IF Almost minimax design of FIR filter using an IRLS algorithm without matrix inversion [10443-52]

$104431 G \quad$ Real time eye tracking using Kalman extended spatio-temporal context learning [10443-14]

$104431 \mathrm{H} \quad$ An improved MTI filter for ground clutter reduction in UAV classification [10443-48]

$1044311 \quad$ Mining maximal approximate numerical frequent patterns from uncertain data and application for emitter entity resolution [10443-24]

$104431 \mathrm{~J}$ Assessing effect of meditation on cognitive workload using EEG signals [10443-41]

10443 1K Cloud storage based mobile assessment facility for patients with post-traumatic stress disorder using integrated signal processing algorithm [10443-68]

10443 1L Analytic radar micro-Doppler signatures classification [10443-33]

\section{SESSION 8 COMPUTER INFORMATION THEORY AND TECHNOLOGY}

$104431 \mathrm{M} \quad$ Mining strong jumping emerging patterns with a novel list data structure [10443-32]

$104431 \mathrm{~N} \quad$ Study of the similarity function in Indexing-First-One hashing [10443-5]

1044310 Heterogeneous computing for a real-time pig monitoring system [10443-3]

10443 IP Deep learning application: rubbish classification with aid of an android device [10443-25]

$104431 Q \quad$ A curriculum-based approach for feature selection [10443-56] 


\section{Authors}

Numbers in the index correspond to the last two digits of the seven-digit citation identifier (CID) article numbering system used in Proceedings of SPIE. The first five digits reflect the volume number. Base 36 numbering is employed for the last two digits and indicates the order of articles within the volume. Numbers start with 00, 01, 02, 03, 04, 05, 06, 07, 08, 09, 0A, 0B...0Z, followed by 10-1Z, 20-2Z, etc.

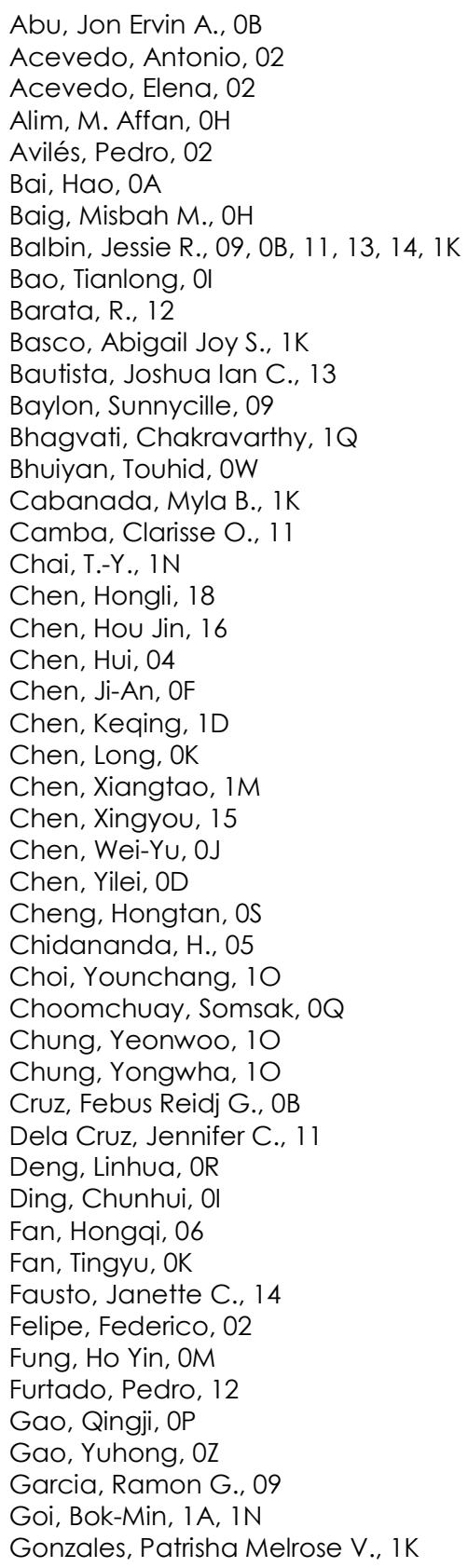

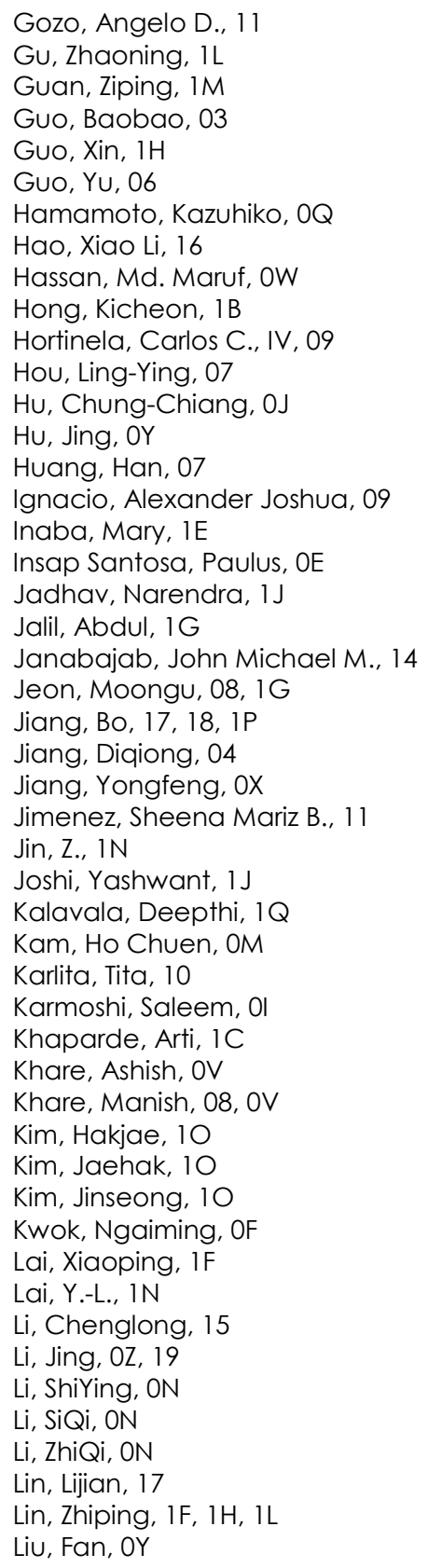


Liv, Qinglai, $1 \mathrm{H}$

Liu, Sijiang, 17, 18, 1P

Liu, Wenping, OX

Liu, Ying, OD

Liv, Zhaoguang, OS

Low, Cheng-Yaw, OG

Luo, Qijun, OP

Malicdem, Daryl James L., 14

Manthalkar, Ramchandra, $1 \mathrm{~J}$

Marasigan, Juan Carlos C., IK

Marcelo, Reginald N., 14

Mehboob, Shahzain, $\mathrm{OH}$

Mehtre, B. M., OT

Meng, Lei, 04

Minhas, Fayyaz ul Amir Asfar, $1 G$

Mu, Zhichun, OK

Munir, Farzeen, IG

Mustafa, Adnan A. Y., OU

Naseem, Imran, $\mathrm{OH}$

Nebres, Pauline D., 13

$\mathrm{Ng}$, Choon-Boon, $1 \mathrm{~A}$

Ning, XiaoLan, ON

Nishino, Kaneharu, 1E

Novita Sari, Felisia, OE

Oh, Beom-Seok, $1 \mathrm{~L}$

P. K., Rajani, 1C

Pang, Zengyao, OD

Park, Daihee, 10

Park, Junghun, 1B

Pereira, J., 12

Pinugu, Jasmine Nadja J., 13, $1 \mathrm{~K}$

Purnama, I. Ketut Eddy, 00, 10

Purnomo, Mauridhi Hery, 00, 10

Rana, Md. Shohel, OW

Reddy, T. Hanumantha, 05

Rey Hipolito, Cipriano M., IV, 13

Rivera, Marco Antonio, 09

Santella, Jose Anthony A., 13

Santos, Jan Jeffrey Z., 14

Sardjono, Tri Arief, 00

Sarker, Kaushik, OW

Sebastian, Jaimie, 09

Shima, Yoshihiro, OL

Siew, Kar Fai, OC

Siño, Carlo G., OB

Song, Rui, 04

Srivastava, Prashant, oV

Sun, Jiande, 03, 0Z, 19

Sun, Lei, IF

Sunarya, I. Made Gede, 00

Sunu, Ismoyo, 00

Tang, Jin, 15

Tang, Xin Jie, OC

Tay, Yong-Haur, OC, IA

Teoh, Andrew Beng-Jin, OG

Ting, Yi-Siang, OF

Toh, Kar-Ann, 1F, 1L

Tribiana, Aivje C., 11

Tsui, Kwan Pang, OM

Ubaldo, Paolo E., OB
V. T., Manu, OT

Wan, Fangyuan, $1 \mathrm{H}$

Wan, Wenbo, $\mathrm{OZ}$

Wang, Chen, $1 \mathrm{H}$

Wang, Fang, 07

Wang, Guan, $1 \mathrm{~L}$

Wang, Haili, OX

Wibirama, Sunu, OE

Win, Khin Yadanar, $O Q$

Wong, Kin Hong, OM

Wu, Cengceng, OS

Wu, Frank, OJ

Wu, Qiang, 03, $0 Z$

Wu, Song, 17

Xia, Ping, 19

Xiao, Huaitie, 06

$\mathrm{Xu}$, Cheng, ON

$X u, X i n, 11$

Yan, Hua, 03, 19

Yan, Liuting, OY

Yan, Mengzhen, 18

Yang, Jie, OD

Yang, Ruyin, OK

Ye, Yang Yang, 16

Yin, Deyu, OP

$Y U$, Ying Kin, $O M$

Yu, Ying-Hao, OF

Yuniarno, Eko Mulyanto, 00, 10

Zhan, Jie, IP

Zhang, Liang, OX

Zhang, Xi-wen, OA

Zhao, Ruijie, $1 \mathrm{~F}$

Zhu, Ming, 0 l

Zhu, Yongfeng, 06

Zulveta, Christelle Jianne T., OB 


\title{
Conference Committees
}

\author{
Conference Chair
}

Xudong Jiang, Nanyang Technological University (Singapore)

Conference Co-chairs

Masayuki Arai, Teikyo University (Japan)

Giovanni Maria Farinella, Università degli Studi di Catania (Italy)

Jin Young Choi, Seoul National University (Korea, Republic of)

Kin Hong Wong, The Chinese University of Hong Kong

(Hong Kong, China)

Technical Program Committee

Qiu Chen, Kogakuin University (Japan)

P. K. Subash Jayasinghe, University of Ruhuna (Sri Lanka)

Jiande Sun, Shandong Normal University (China)

Osama Halabi, Qatar University (Qatar)

Bhupendra Gupta, Indian Institute of Information Technology Design and Manufacturing Jabalpur (India)

Kuo-Liang Chung, National Taiwan University of Science and Technology (Taiwan)

Andrew B. J. Teoh, Yonsei University (Korea, Republic of)

Xiaoyi Jiang, Universität Münster (Germany)

Giuseppe Serra, Università degli Studi di Modena e Reggio Emilia (Italy)

Julian Fierrez, Universidad Autónoma de Madrid (Spain)

Zeng Xiangrong, National University of Defense Technology (China)

K. Seetharaman, Annamalai University (India)

Yau Hee Kho, Nazarbayev University (Kazakhstan)

Julia Sidorova, Blekinge Institute of Technology (Sweden)

Wei Jia, Hefei University of Technology (China)

Xianfang Sun, Cardiff University (United Kingdom)

Reinhard Klette, Auckland University of Technology (New Zealand)

Liping Wang, Aberystwyth University (United Kingdom)

Kuo-Chin Fan, National Central University (Taiwan)

Deepak Ghimire, Korea Electronics Technology Institute

(Korea, Republic of)

Bo Jiang, Nanjing University of Posts and Telecommunications (China) Juno Kim, The University of New South Wales (Australia)

Iping Supriana, Institut Teknologi Bandung (Indonesia)

Yong Haur Tay, Universiti Tunku Abdul Rahman (Malaysia) 
Bok-Min Goi, Universiti Tunku Abdul Rahman (Malaysia)

Beom-Seok Oh, Nanyang Technological University (Singapore)

Xu Cheng, Hunan University (China)

Mahesha Kapurubandara, Sri Lanka Institute of Information

Technology (Sri Lanka)

Young-Woong Ko, Hallym University (Korea, Republic of)

Lei Meng, Nanyang Technological University (Singapore)

José-Miguel Benedí, Universitat Politècnica de València (Spain)

M. Ali Akber Dewan, Athabasca University (Canada)

Chih-Yi Chiu, National Chiayi University (Taiwan)

loannis Pratikakis, Democritus University of Thrace (Greece)

Cheng Jin, Fudan University (China)

Michele Nappi, Università degli Studi di Salerno (Italy)

Yong Tsui Lee, Nanyang Technological University (Singapore)

Fatih Demirci, TOBB University of Economics and Technology (Turkey)

Stefanos Kollias, National Technical University of Athens (Greece)

Francisco Herrera, Universidad de Granada (Spain)

Su Yang, Fudan University (China)

Moongu Jeon, Gwangju Institute of Science and Technology

(Korea, Republic of)

Abdul Jalil, International Islamic University (Pakistan)

Liang Zhang, Civil Aviation University of China (China)

Xiwen Zhang, Beijing Language and Culture University (China)

Linhua Deng, Yunnan Observatory, Chinese Academy of Sciences (China)

Yiu-ming Cheung, Hong Kong Baptist University (Hong Kong, China)

Yang Yang, University of Electronic Science and Technology of China (China)

Somsak Choomchuay, King Mongkut's Institute of Technology

Ladkraban (Thailand)

Pedro Furtado, Universidade de Coimbra (Portugal)

Touhid Bhuyian, Daffodil International University (Bangladesh)

Yongwha Chung, Korea University (Korea, Republic of)

Houjin Chen, Beijing Jiaotong University (China)

Mei Li, China University of Geosciences (China)

Reviewers

Renoh Johnson Chalakkal, The University of Auckland (New Zealand)

T. Hanumanth Reddy, Rao Bahadur Y Mahabaleshwarappa

Engineering College (India)

Rui Song, Shandong University (China)

Fang Wang, Nanchang Institute of Technology (China)

M. Zorkany, National Telecommunication Institute (Egypt)

Manish Khare, Gwangju Institute of Science and Technology

(Korea, Republic of)

Zhe Jin, Universiti Tunku Abdul Rahman (Malaysia) 
Fayyaz UI Amir Afsar Minhas, Pakistan Institute of Engineering and Applied Sciences (Pakistan)

Adnan Mustafa, Kuwait University (Kuwait)

Gaurav Bhatnagar, University of Windsor (Canada)

Arti Khaparde, Maharashtra Institute of Technology (India)

Arnold Paglinawan, Mapúa Institute of Technology (Philippines)

Yashawant Joshi, Shri Guru Gobind Singhji Institute of Engineering \& Technology (India)

Mauridhi Hery Purnomo, Institut Teknologi Sepuluh Nopember (Indonesia)

Alejandro Jr Ballado, Mapúa Institute of Technology (Philippines)

Quan Thanh Tho, Bach Khoa University (Vietnam)

Neeraj Tiwari, Shri Ramswaroop Memorial University (India)

Ying-Hao Yu, National Chung Cheng University (Taiwan)

Ngaiming Kwok, The University of New South Wales (Australia)

Tsung-Nan Chou, Chaoyang University of Technology (Taiwan)

\section{Session Chairs}

1 Face Recognition

Kin Hong Wong, The Chinese University of Hong Kong (Hong Kong, China)

2 Image Analysis and Transformation

Juno Kim, The University of New South Wales (Australia)

3 Image Processing and Application

Pedro Furtado, Universidade de Coimbra (Portugal)

4 Signal Analysis and Processing

Mei Li, China University of Geosciences (China)

5 Target Recognition

Kar-Ann Toh, Yonsei University (Korea, Republic of)

6 Feature Detection and Matching

Zhiping Lin, Nanyang Technological University (Singapore)

7 Image Segmentation and Video Processing Technology

Yoshihiro Shima, Meisei University (Japan)

8 Computer Theory and Application

Bok-Min Goi, Universiti Tunku Abdul Rahman (Malaysia) 
Proc. of SPIE Vol. 10443 1044301-12 Downloaded From: https://www.spiedigitallibrary.org/conference-proceedings-of-spie on 26 Apr 2023
Terms of Use: https://www.spiedigitallibrary.org/terms-of-use 


\section{Introduction}

In recent years, pattern recognition has become a hot research branch in the field of machine learning. In light of the fast-paced advancements in pattern recognition taking place all over the world, it is of interest to keep an eye on the state-of-the-art research and development and to facilitate collaboration in multidisciplinary research areas. With this end in view, the Second International Workshop on Pattern Recognition was held 1-3 May 2017 in Singapore.

The aim of the conference is to address and deliberate on the latest technical status and recent trends in the research and applications of pattern recognition. This conference has been designed with the view to provide an opportunity for the scientists, engineers, industrialists, students and other professionals from all over the world to interact and exchange their new ideas and research outcomes for future collaboration.

This year, IWPR solicited 113 submitted papers from different countries all over the world. The Proceedings of IWPR 2017 contains 61 selected papers from the conference, which were presented orally or via poster sessions, and provide up-todate, comprehensive and worldwide state-of-the-art knowledge in this field. Each contributed paper was rigorously reviewed by members of our international organizing and advisory committees, and external reviewers in related fields from all over the world. The Proceedings covers the specific areas as follows: target recognition and tracking, face recognition, image segmentation, image transformation and analysis, medical image analysis and processing, image processing and application, filter design and signal processing, computer information theory and technology.

On behalf of the Organizing Committee, we would like to express our heartfelt gratitude to all the reviewers for their great professionalism and efforts. Thank you to all the participants and sponsors for their valuable contributions and support to IWPR 2017. 
Proc. of SPIE Vol. 10443 1044301-14 Downloaded From: https://www.spiedigitallibrary.org/conference-proceedings-of-spie on 26 Apr 2023
Terms of Use: https://www.spiedigitallibrary.org/terms-of-use 